\title{
Family history as a risk factor for recurrent hospitalization for lone atrial fibrillation: a nationwide family study in Sweden
}

\author{
Bengt Zöller ${ }^{1 *}$, Henrik Ohlsson ${ }^{1}$, Jan Sundquist ${ }^{1,2}$ and Kristina Sundquist ${ }^{1,2}$
}

\begin{abstract}
Background: Although the heritability of atrial fibrillation (AF) has been determined, the relevance of family history of AF for the likelihood of recurrent hospitalization for AF is unknown. The aim of this nationwide study was to determine whether family history of $A F$ is a risk factor of recurrent hospitalization for lone AF (LAF), i.e., AF with unknown etiology. The familial risk for first time LAF hospitalization was also determined and compared to the risk of recurrent hospitalization for LAF.
\end{abstract}

Methods: We examined whether family history of AF is a risk factor for recurrent hospitalization for LAF in the whole Swedish population. We linked Multigeneration Register data on individuals aged 0-60 years to Hospital Discharge Register data for the period 1987-2009 to compare LAF recurrent hospitalization risk among individuals with and without parental or sibling history of AF. We calculated hazard ratios (HRs) to determine the familial HR of recurrent hospitalization for LAF. Odds ratios (OR) were calculated for familial risk of first time LAF hospitalization.

Results: The risk of recurrent LAF hospitalization was 1.23 (95\% Cl 1.17-1.30) for individuals with affected parents compared to 1.30 (95\% Cl 1.22-1.38) for those with affected siblings. After 10 years of follow up $50 \%$ of those without and $60 \%$ of those with family history had recurrent hospitalization for LAF. The risk of recurrent LAF hospitalization in individuals with two affected parents was 1.65 (95\% Cl 1.44-1.90). There was an interaction between age and family history, with family history having a weaker effect on LAF hospitalization risk in older age groups. The OR for first time LAF hospitalization was 2.08 (95\% Cl 2.02-2.15) for offspring with affected parents and 3.23 (95\% Cl 3.08-3.39) for individuals with affected siblings.

Conclusions: Family history of AF is a novel risk factor for recurrent LAF hospitalization. The higher recurrence hospitalization risk in multiplex families and younger individuals suggests a genetic contribution. However, the familial risk for recurrent LAF hospitalization was much lower than the risk for first time LAF hospitalization, suggesting that familial and possibly genetic factors are more important for first time LAF hospitalization than recurrent LAF hospitalization.

Keywords: Atrial fibrillation, Family history, Risk factors, Genetics

\footnotetext{
* Correspondence: bengt.zoller@med.lu.se

${ }^{1}$ Center for Primary Health Care Research, CRC, Skåne University Hospital, Building 28, Floor 11, Jan Waldenströms gata 35, Malmö S-205 02, Sweden Full list of author information is available at the end of the article
} 


\section{Background}

Atrial fibrillation (AF) is a major public health problem because of its increasing prevalence and because it is associated with increased morbidity and mortality [1,2]. Many risk factors for AF have been described and they include, e.g., old age, cardiomyopathy, valvular disease, ischemic heart disease, heart failure, thyroid disease, hypertension and diabetes mellitus [1-3]. In some patients, its etiology remains unknown. AF occurring before the age of 60 years without any evidence of associated cardiopulmonary or other comorbid disease has been termed lone AF (LAF) $[4,5]$. Familial AF was first reported in 1943 [6], and familial clustering of AF has been repeatedly demonstrated [7-15]. The first chromosomal location of an AF susceptibility gene was reported in 1997 based on genetic mapping studies in three families [16]. Several genetic variants have since then been linked to risk of AF [17-25]. The importance of family history for LAF has been determined in several studies $[9,11,12,14]$.

Despite the use of antiarrhythmic agents for sinus rhythm maintenance in cardioverted AF patients, a considerable proportion of patients relapse to AF [2]. It is generally believed that these recurrences are associated with older age, atrial dilatation, and long duration of AF [26]. Studies have also suggested that female sex, obesity, personal history of two or more AF events, decreased renal function, increased circulating markers of cardiomyocyte injury/strain (high-sensitivity troponin $\mathrm{T}, \mathrm{N}$ terminal probrain natriuretic peptide and mid-regional proatrial natriuretic peptide) and endothelin, and increased $\mathrm{C}$-reactive protein to be risk factors for relapse to AF [26-32]. The tendency of AF to become sustained over time is not easily managed, and represents a challenging therapeutic problem. Although family history is a risk factor for first event of AF [6-15], the risk of AF recurrence in patients with a family history of AF has not yet been determined.

In this nationwide study, we investigated the relationship between family history of AF and the risk of recurrent hospitalization for LAF. The familial risk for first LAF hospitalization was also determined and compared to the risk of recurrent hospitalization for LAF.

\section{Methods}

To assess LAF among individuals in Sweden, comprehensive register and health care data from multiple nationwide sources were linked [33-37]. This linking was based on the unique 10-digit personal ID numbers assigned at birth or immigration to all Swedish residents for life, information on which is nearly $100 \%$ complete. These numbers were replaced with serial numbers to preserve anonymity. Our database contains data from four sources:
1. The Swedish Multigeneration Register, which contains information on family relationships (siblings, parent-offspring). The register contains information on index persons registered in Sweden between January 1, 1961 and December 31, 2008 and born between January 1, 1932 and December 31, 2008.

2. The Swedish Hospital Discharge Register, which contains information on all hospital diagnoses for all people in Sweden for the period 1987-2009. Each record includes the main discharge diagnosis.

3. The Swedish Cause of Death Register, which contains data on date of death for the period 1961-2010.

4. The Total Population Register, which includes data on year of birth, gender, country of birth and education.

This study was approved by the Ethics Committee of Lund University, Sweden.

\section{Variable definition}

Cases of LAF were identified in the Swedish Hospital Discharge Register by the use of the ICD (International Classification of Diseases) codes 427D (ICD-9) and I48 (ICD-10) and age $\leq 60$ years at the first diagnosis of AF. Individuals with one or more of the following discharge diagnoses within the 5-year period prior to the first diagnosis of AF were excluded: Hypertension (401-405 (ICD-9) and (I10-I15 (ICD-10)); Heart failure (428 (ICD9) and I50 (ICD-9)); Coronary heart disease (410-414 (ICD-9) and I20-I25 (ICD-9)); Morbi rheumatici cordis and Valvular disease (390-398, 421 and 424 (ICD-9) and I00-I09 and I33-I39 (ICD-10)); Cardiomyopathy (425 (ICD-9) and I42 and I43 (ICD-10)); Myocarditis (422 (ICD-9) and I40 and I41 (ICD-9)); Pericarditis (420 (ICD-9) and I30-I32 (ICD-10)); Other heart disease (429 (ICD-9) and I51 (ICD-10)); Thyrotoxicosis (242 (ICD-9) and E05 (ICD-10)); and Diabetes mellitus (250 (ICD-9) and (E10-E14 (ICD-10)). These diagnoses, together with the same diagnoses from the Cause of Death Register, were also used to define cardiovascular disease (CVD) outcome in model 1.G (see below).

AF in parents and siblings was defined by the ICD codes 427D (ICD-9) and I48 (ICD-10). Parental history of $\mathrm{AF}$ was defined as $\mathrm{AF}$ in at least one parent during the study period. Sibling history of AF was defined as $\mathrm{AF}$ in at least one sibling sometime during the study period.

The validity of the diagnosis of AF has been evaluated, and diagnoses were found to be correct in $97 \%$ of cases in the Hospital Discharge Register [37,38]. Diagnoses of other cardiovascular disorders such as stroke and myocardial infarction have an approximate 95\% validity [37]. Generally, the validity in the Hospital Discharge Register is approximately $85-95 \%$ [37]. 


\section{Sample}

The analyses were based on a database containing information on all cases of LAF during the period 1987-2009 $(n=29,660$, mean age $=50.1$ years $(S D=9.6), 74 \%$ men, $A F$ recurrence rate $=49.6 \%$ ).

\section{Statistical methods}

We used Cox proportional hazards models in order to investigate recurrence of AF within 10 years. Cases were followed from date of LAF diagnosis during the study period until AF recurrence, death, emigration or the end of the follow-up period (December 31, 2009 or a maximum of 10 years) (whichever came first). In the first analysis, a parent-offspring analysis, we investigated all LAF proband cases whose parents both lived in Sweden sometime between 1987 and $2009(n=16,160)$. In model 1.A, parental history of AF was included as a covariate (yes/no), and in model 1.B we also included sex, age at diagnosis of LAF (centered at the mean value), and terms for the interaction between parental history of AF and age/sex. The interaction terms were only included in the model if the p-values were $<0.05$. In model 1.C the variable parental history was categorized as no parental history of AF, one parent with AF and two parents with AF. In model 1.D, we investigated the association of parental history of LAF with time to first recurrence of AF in proband cases.

In order to further evaluate the results, we also investigated time from first until second recurrence of $\mathrm{AF}$ (model 1.E), as well as time from diagnosis of LAF until second recurrence of AF (model 1.F, $n=7,370$ ). We additionally investigated time to first recurrence of AF in individuals who did not experience any other CVD outcome during the 10-year follow-up period (model 1.G, $\mathrm{n}=9,071)$.

In the second analysis, a sibling analysis, we examined all LAF proband cases with at least one sibling living in Sweden sometime between 1987 and 2009 ( $n=20,373)$. In model 2.A, sibling history of AF was included as a covariate (yes/no), and in model 2.B we also included sex, age at diagnosis of LAF (centered at the mean value), and terms for the interactions between sibling history of AF and age/sex. The interaction terms were only included in the model if the p-values were $<0.05$. We also adjusted both models for number of siblings to the proband case (not reported in the tables).

In the third analysis, we merged datasets I and II and only analyzed individuals who were included in both datasets (13,525 cases). In model 3.A, sibling history of $\mathrm{AF}$ and parental history of AF were included as covariates (yes/no), and in model 3.B we also included sex, age at diagnosis of LAF (age at LAF), terms for the interactions between sibling history of AF and parental history of AF and terms for the interactions between sibling history of AF/parental history of AF and age/sex. The interaction terms were only included in the model if the p-values were $<0.05$.

In order to take into account the non-independence of observations from the same family, we used a robust sandwich estimator in all models [34,35]. We present hazard ratios (HRs) and the corresponding 95\% CIs [39]. The proportional hazards assumption was fulfilled for the variables of interest.

In order to investigate familial transmission of first time LAF hospitalization we used a case-cohort approach to determine familial risks with odds ratios (ORs) [34,35]. We conducted two main analyses: proband-sibling and proband-parent. In these analyses, we studied all LAF proband-relative pairs that could be matched to five control pairs in the Swedish population. For example, in the proband-sibling analysis we selected all sibling pairs for which at least one sibling was diagnosed with LAF and matched each of them to five control pairs. The control pairs were chosen randomly from individuals who lived in Sweden at the time of the probands' diagnosis of LAF and comprised pairs of individuals who were not diagnosed with LAF or AF prior to the time of the proband's diagnosis of LAF. Furthermore, both individuals in the control pair also had to have lived in Sweden sometime during the period 1987-2009. Control pairs were matched based on year of birth, sex, country of birth and level of education (the year before the date of diagnosis). Analyses were conducted by conditional logistic regression [34,35]. As an example, in the proband-sibling analysis, AF in sibling (yes/no) was used as the independent variable. We present odds ratios (ORs) and the corresponding 95\% CIs, according to previous studies of familial risks [34,35]. As a proband could be included several times, we adjusted for nonindependence by using a robust sandwich estimator [34,35]. In all analyses, less than $1 \%$ of the proband pairs could not be matched to five controls and were excluded from the analysis.

All calculations were performed using SAS version 9.3.

\section{Results}

There were 16,160 individuals with LAF in families in which both parents were alive sometime during the study period (Table 1). $45.6 \%$ of them had recurrent hospitalization for AF. $26.9 \%$ of individuals with recurrence had a parent with $\mathrm{AF}$, compared to $21.6 \%$ of those without recurrence. There were 20,373 individuals with LAF in families in which at least one sibling was alive sometime during the study period. $48.6 \%$ of them had recurrent hospitalization for AF. $11.6 \%$ of the individuals with recurrence had at least one sibling diagnosed with AF during the study period. The corresponding number for non-recurrent cases was $7.7 \%$. 
Table 1 Descriptive statistics for individuals with lone atrial fibrillation (LAF) in the Swedish population (1987-2009)

\begin{tabular}{|c|c|c|c|c|}
\hline & \multicolumn{2}{|c|}{$\begin{array}{l}\text { Individuals diagnosed with LAF and with both } \\
\text { parents living in Sweden sometime during } \\
1987-2009(\mathrm{n}=16,160)\end{array}$} & \multicolumn{2}{|c|}{$\begin{array}{l}\text { Individuals diagnosed with LAF and with at least } \\
\text { one sibling living in Sweden sometime during } \\
1987-2009 \text { ( } n=20,373)\end{array}$} \\
\hline & Recurrence & No Recurrence & Recurrence & No Recurrence \\
\hline $\mathrm{N}$ & 7,375 & 8,785 & 9,909 & 10,464 \\
\hline AF parents & $26.9 \%$ & $21.6 \%$ & & \\
\hline LAF parents & $2.7 \%$ & $2.5 \%$ & & \\
\hline AF siblings & & & $11.6 \%$ & $7.7 \%$ \\
\hline Men & $79.0 \%$ & $75.8 \%$ & $77.2 \%$ & $74.1 \%$ \\
\hline Age at diagnosis of LAF, mean (SD) & $48.3(10.1)$ & $46.3(11.1)$ & $50.5(9.0)$ & $48.6(10.7)$ \\
\hline
\end{tabular}

Table 2, model 1.A shows that proband cases with parents diagnosed with AF had a 1.23 times higher hazard (95\% CI 1.17-1.30) for recurrent AF hospitalization than proband cases without parental history. This number was not attenuated when age and sex were included in the model (Table 2, model 1B). However, there seemed to be an interaction between age at diagnosis of $\mathrm{AF}$ among parents (HR 0.99, 95\% CI 0.99-0.99), indicating a decreased association of parental $\mathrm{AF}$ on recurrent $\mathrm{AF}$ the older the case. Model 1.C indicates that the HR was higher for proband cases with two affected parents (HR $1.65,95 \%$ CI 1.44-1.90) than for proband cases with only one affected parent (HR 1.16, 95\% CI 1.10-1.23). Model 1.D shows that proband cases with parents diagnosed with LAF had a 1.42-fold higher hazard rate for recurrent AF hospitalization. While model 1.E shows that parental history is less important when investigating time between second and third episodes of AF, model 1.F shows that the HR for parental history is similar when investigating time from first to second episode of $\mathrm{AF}$ and time from first to third episode of AF. The HR in model 1.G (in which all cases with a CVD diagnosis in the 10 years after first AF hospitalization were excluded) is similar to the HR in model 1.A. This indicates that the results in model 1.A are not confounded by other CVD outcomes. Figure $1 \mathrm{~A}$ shows that at the end of the follow-up period, approximately $60 \%$ of proband cases with parental history of AF had recurrent hospitalization for AF; the corresponding number for proband cases without parental history was $50 \%$.

Table 3, model 2.A shows that proband cases with at least one sibling diagnosed with AF had a 1.30-fold higher hazard rate $(95 \% \mathrm{CI} 1.22-1.38)$ for recurrent $\mathrm{AF}$ hospitalization than proband cases without sibling history. However, model 2.B shows that the risk of LAF associated with sibling history differed between men and

Table 2 Results from Cox proportional hazard models for individuals with LAF in the Swedish population (1987-2009): parent-offspring analysis $(n=16,160)$

\begin{tabular}{|c|c|c|c|c|}
\hline Variable & Model 1.A & Model 1.B & Model 1.C & Model 1.D \\
\hline & $\mathrm{HR}(95 \% \mathrm{Cl})$ & $\mathrm{HR}(95 \% \mathrm{Cl})$ & $\mathrm{HR}(95 \% \mathrm{Cl})$ & $\mathrm{HR}(95 \% \mathrm{Cl})$ \\
\hline AF in parent(s) (yes/no) & $1.23(1.17-1.30)$ & $1.22(1.15-1.28)$ & & \\
\hline $\mathrm{AF}$ in 1 parent & & & $1.16(1.10-1.23)$ & \\
\hline AF in 2 parents & & & $1.65(1.44-1.90)$ & \\
\hline LAF in parent(s) (yes/no) & & & & $1.42(1.23-1.63)$ \\
\hline Sex (Reference: females) & & $1.20(1.13-1.27)$ & $1.20(1.13-1.27)$ & $1.20(1.13-1.27)$ \\
\hline Age at diagnosis of LAF (yearly increase) & & $1.02(1.02-1.02)$ & $1.02(1.02-1.02)$ & $1.02(1.02-1.02)$ \\
\hline \multirow[t]{3}{*}{ Age at diagnosis of AF in parent(s) } & & $0.99(0.99-0.99)$ & & \\
\hline & Model 1.E & Model 1.F & Model 1.G & \\
\hline & $\mathrm{HR}(95 \% \mathrm{Cl})$ & $\mathrm{HR}(95 \% \mathrm{Cl})$ & HR $(95 \% \mathrm{Cl})$ & \\
\hline AF in parent(s) & $1.07(1.00-1.14)$ & $1.22(1.15-1.31)$ & $1.23(1.15-1.31)$ & \\
\hline Sex (Reference: females) & $1.05(0.97-1.13)$ & $1.22(1.14-1.31)$ & $1.22(1.14-1.31)$ & \\
\hline Age at diagnosis of LAF (yearly increase) & $1.00(1.00-1.01)$ & $1.02(1.02-1.02)$ & $1.02(1.02-1.02)$ & \\
\hline
\end{tabular}

Model 1.A: HR of parental history of AF. Model 1B: also included sex, age at diagnosis of LAF (centered at the mean value), and terms for the interaction between parental history of $\mathrm{AF}$ and age/sex. The interaction terms were only included in the model if the $\mathrm{p}$-values were $<0.05$. Model $1 \mathrm{C}$ : the variable parental history was categorized as no parental history of AF, one parent with AF and two parents with AF. Model 1D: the association of parental history of LAF with time to first recurrence of $A F$ in proband cases in proband cases was determined. Model $1 \mathrm{E}$ : time from first until second recurrence of $A F$ was used to calculate the familial HR. Model 1F: time from diagnosis of LAF until second recurrence of AF was used. Model 1G: time to first recurrence of AF in individuals who did not experience any other CVD outcome during the 10-year follow-up period was used to calculate HR. 

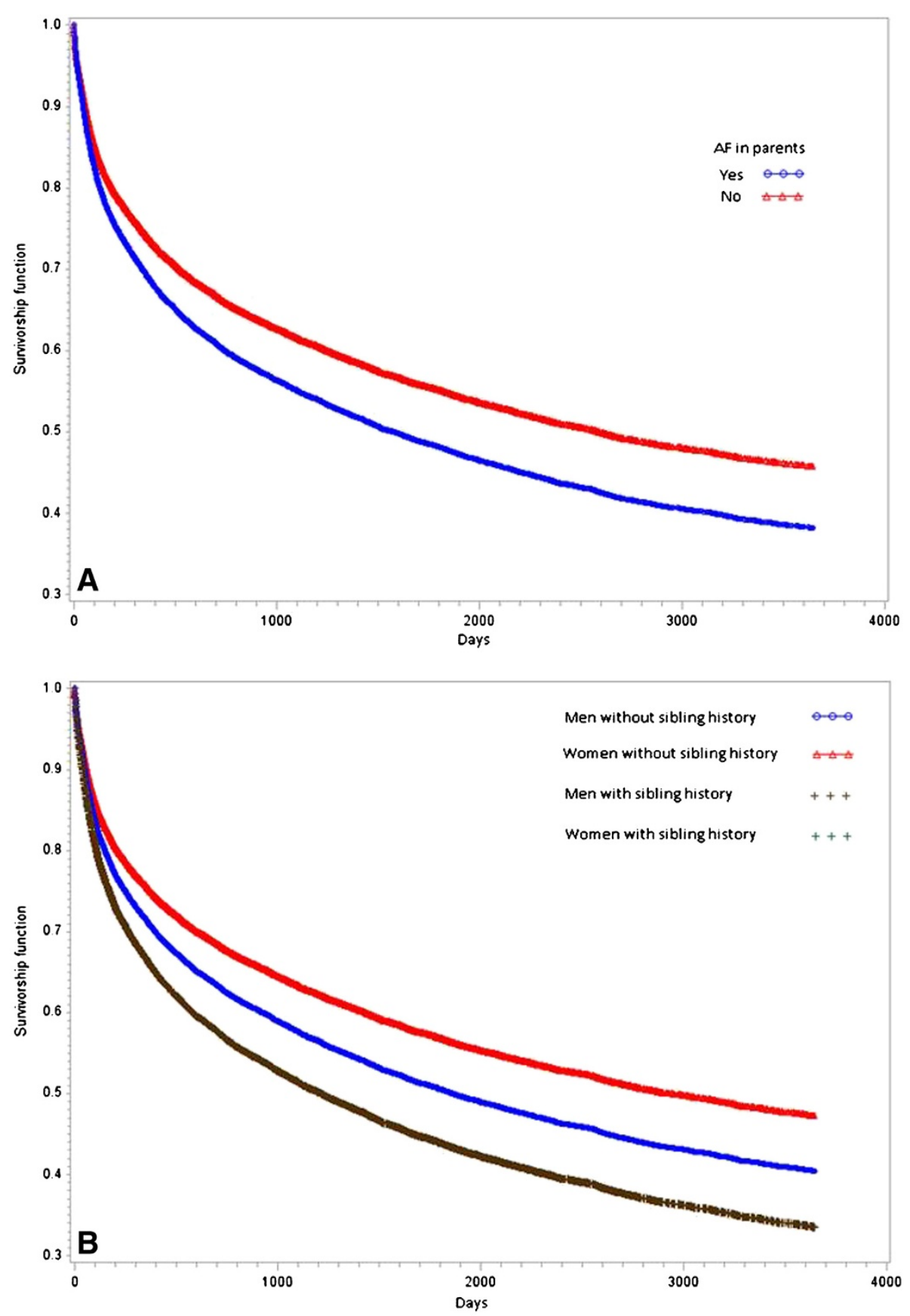

Figure 1 A (left) Survivorship function for model 1.A, i.e. parental history of AF (yes/no). B (right) Survivorship function for model 2.A, ie. sibling history of AF (yes/no). Note that the survivorship function for men with sibling history of AF overlaps with the survivorship function for women with sibling history of AF.

women (HR for interaction term 0.83 , 95\% CI 0.72 0.95). This indicates that even though men had a higher risk of recurrent AF hospitalization (HR 1.21), the effect of AF among siblings was more important for women than for men. Figure 1B shows the survivorship function from model 2.B, indicating that at the end of the followup period $65 \%$ of individuals with at least one sibling with AF had recurrent hospitalization for AF. This number was the same for both men and women. Model 3.A shows that the HR was similar for parental and sibling history of AF (HR 1.21 and 1.28, respectively).

Familial risk of first time LAF hospitalization was determined for comparison with recurrent risk only. Table 4 shows the results of the case-cohort analysis. 
Table 3 Results from Cox proportional hazard models for individuals with LAF in the Swedish population (1987-2009): sibling analysis $(n=20,373)$ and parent-sibling analysis $(n=13,525)$

\begin{tabular}{|c|c|c|c|c|}
\hline & Model 2.A & Model 2.B & Model 3.A & Model 3.B \\
\hline & HR (95\% Cl) & HR (95\% Cl) & HR (95\% Cl) & HR (95\% Cl) \\
\hline AF in sibling(s) (yes/no) & $1.30(1.22-1.38)$ & $1.46(1.30-1.65)$ & $1.28(1.18-1.39)$ & $1.48(1.24-1.75)$ \\
\hline $\mathrm{AF}$ in parent(s) & & & $1.21(1.14-1.28)$ & $1.16(1.10-1.23)$ \\
\hline Sex (Reference: females) & & $1.21(1.15-1.27)$ & & $1.26(1.18-1.34)$ \\
\hline Age at diagnosis of AF (yearly increase) & & $1.02(1.02-1.02)$ & & $1.02(1.02-1.02)$ \\
\hline AF in Sibling (age at diagnosis of AF) & & $0.99(0.98-0.99)$ & & \\
\hline AF in sibling (sex) & & $0.83(0.72-0.95)$ & & $0.76(0.63-0.93)$ \\
\hline AF in parent(s) (age at diagnosis of AF) & & & & $0.99(0.98-0.997)$ \\
\hline
\end{tabular}

Model 2.A: sibling history of AF was included as a covariate (yes/no). Model 2.B: we also included sex, age at diagnosis of LAF (centered at the mean value), and terms for the interactions between sibling history of $A F$ and age/sex. The interaction terms were only included in the model if the $p$-values were $<0.05$. Both model $2 \mathrm{~A}$ and $2 \mathrm{~B}$ were adjusted for the number of siblings to the proband case. Model 3.A, sibling history of AF and parental history of AF were included as covariates (yes/no). Model 3.B: included sex, age at diagnosis of LAF (age at LAF), terms for the interactions between sibling history of AF and parental history of $A F$ and terms for the interactions between sibling history of AF/parental history of AF and age/sex. The interaction terms were only included in the model if the p-values were $<0.05$.

$14.2 \%$ of the proband cases had a parent diagnosed with AF. The OR for the parent-offspring analysis was 2.08 (95\% CI 2.02-2.15), which can be interpreted as a 2-fold increase in the odds of AF in the parents of proband cases diagnosed with LAF compared to the parents to controls. The sibling analysis revealed that $5.3 \%$ of the proband cases had a sibling diagnosed with AF. The OR was 3.23 (95\% CI 3.08-3.39), indicating more than 3-fold higher odds of AF siblings of individuals diagnosed with LAF compared to the siblings of controls.

\section{Discussion}

The present study is, to our knowledge, the first nationwide study to estimate the familial risk of recurrent hospitalization for LAF. Previous studies have only investigated the familial risk of a first AF event [6-15]. The present study found similar familial risks for first time LAF event to those reported previously [6-15]. The familial risk for recurrent LAF hospitalization was lower than the risk for first time LAF hospitalization, suggesting that familial and possibly genetic factors are more important for first time LAF hospitalization than recurrent LAF hospitalization. Our findings indicate that family history of AF is a new risk factor for recurrent hospitalization for LAF. The higher risk for recurrent

Table 4 Familial risk of first time LAF hospitalization in individuals with parental or sibling history of AF

\begin{tabular}{llll}
\hline $\begin{array}{l}\text { Relationship to } \\
\text { proband }\end{array}$ & $\begin{array}{l}\text { Number of } \\
\text { pairs }\end{array}$ & $\begin{array}{l}\text { Concordant } \\
\text { pairs }\end{array}$ & $\begin{array}{l}\text { OR } \\
(\mathbf{9 5 \%} \mathbf{~ C l )}\end{array}$ \\
\hline Sibling & 40,818 & $2,167(5.3 \%)$ & $3.23(3.08-3.39)$ \\
\hline Parent & 34,657 & $4,906(14.2 \%)$ & $2.08(2.02-2.15)$
\end{tabular}

Results from conditional logistic regression analysis of individuals with LAF in the Swedish population (1987-2009).

*OR ratio was determined according to previous studies of familial risks $[34,35]$.
LAF hospitalization among multiplex families (i.e. two or more affected relatives) may be genetic although nongenetic familial factors cannot be ruled out. There was an interaction between age and family history, with family history having a weaker effect on AF hospitalization risk in older age groups, which further indicates a genetic contribution. Identifying genetic risk factors for AF may have important prognostic value regarding recurrence risk. The mechanism behind the observed familial recurrent LAF hospitalization risk might be genetic or non-genetic. For instance, patients with familial LAF might have a higher AF awareness and possibly have a lower threshold for seeking health care. However, several genetic variants have been linked to risk of AF [16-25]. It is possible that these variants may also predispose individuals to an increased risk of recurrent hospitalization for LAF. Moreover, the dissected underlying familial risk factors (genetic or nongenetic) are likely to have a magnitude that is stronger than the familial risk itself $[40,41]$. For instance, it has been estimated that 10 additive alleles, each with a genotype relative risk of 2.0 and an allele frequency of 0.1 , will only explain a familial risk of 1.06 [41]. If multiplicative gene-gene interactions are present, the same 10 alleles will still only explain a familial risk of 1.2 [41].

Interestingly, there appears to be an interaction between sex and family history, with family history of AF having a greater effect in women than in men in the context of risk of recurrent hospitalization for AF. This suggests that familial and possibly genetic factors might be relatively more important in women than in men regarding recurrent risk of hospitalization for LAF. In individuals without family history of AF, male sex was a risk factor for recurrent LAF. This is opposite to a study that found female sex to be associated with recurrence of AF [27]. However, the patients in that study were 
older and had cardiovascular comorbidities, which may explain the divergent results. We also investigated whether family history of AF is a risk factor for a third recurrent LAF hospitalization. No such association was found. This may be due to that having a personal history of two or more AF is a strong risk factor in itself for recurrent AF [29].

The present study has a number of strengths. These include complete nationwide coverage in a country with high medical standards and medical diagnosis of patients by specialists during examinations in hospitals. In addition, the results were not affected by recall bias because both the probands and cases were medically diagnosed. Importantly, the Multigeneration Register is a validated source that has been proved to be reliable in the study of many familial diseases [33-37].

In order to exclude cardiovascular confounders we excluded all LAF patients who developed CVD during the 10 year follow up period after first LAF hospitalization (Table 2, model 1G). The HR for recurrent LAF hos pitalization was similar, which suggests that the results are not confounded by other CVD outcomes during follow up.

The present study has also a number of limitations. The most important limitation is that we do not know whether recurrent LAF hospitalization is due to a new episode of paroxysmal AF or to the same persistent episode of AF. Thus, the results could reflect an increased risk of recurrent paroxysmal AF or symptomatic persistent AF in familial cases. The increased risk for recurrent hospitalization persisted during the whole follow up period (10 years after first hospitalization), which suggests that our results mainly reflect an increased risk of recurrent paroxysmal AF. Early recurrence could sometimes be due to admittance for elective cardioversion of persistent AF after at least three weeks of treatment with anticoagulation. However, normally elective cardioversion is performed in outpatients.

Longitudinal registers are subject to missing data before the date the register started. The Swedish Hospital Discharge Register only contains complete data for the period since 1987. However, such losses would be similar for both cases and controls and would not affect the estimates of familial aggregation (i.e. the HR). This is most likely a source of non-differential bias regarding familial risk estimates.

Another potential limitation is that we do not have access to the methods used for objective diagnosis. However, the Swedish Hospital Discharge Register has high validity, especially for cardiovascular disorders such as AF (97\%), stroke and myocardial infarction (approximately 95\%) $[37,38]$. However, hypertension is not specifically validated and it is possible that the prevalence of this diagnoses is underestimated. It is therefore possible that some non-LAF cases have been included in the LAF group. This may have underestimated the familial recurrence of LAF, due to dilution of LAF cases with non-LAF cases.

While not all patients may seek help for AF, affordability of healthcare is probably not a selective factor in Sweden because of equal access to primary and hospital care. However, the likelihood of seeking medical advice might be of importance. It is possible that patients with familial LAF might have a higher AF awareness and possibly have a lower threshold for seeking health care. Thus, familial non-genetic factors might also be of importance.

\section{Conclusions}

The present study demonstrates that family history of $\mathrm{AF}$ is a risk factor for recurrent hospitalization for LAF in Swedish patients. Risk of recurrent hospitalization for LAF was especially high in multiplex families and younger individuals, which suggests a genetic contribution. However, the familial risk for recurrent LAF hospitalization was lower than the risk for first time LAF hospitalization, suggesting that familial factors are more important for first time LAF hospitalization than recurrent LAF hospitalization.

\section{Abbreviations}

AF: Atrial fibrillation; LAF: Lone atrial fibrillation; Cl: Confidence interval; HR: Hazard ratio; OR: Odds ratio; ICD: International Classification of Diseases.

\section{Competing interests}

The authors declare that they have no competing interest.

\section{Authors' contributions}

All authors contributed to the conception and design of the study; JS and KS contributed to the acquisition of data; all authors contributed to the analysis and interpretation of data; BZ drafted the manuscript; and all authors revised it critically and approved the final version. All authors had full access to all of the data (including statistical reports and tables) and take responsibility for the integrity of the data and the accuracy of their analysis.

\section{Acknowledgements}

The authors wish to thank the CPF's Science Editor Stephen Gilliver for his useful comments on the text. The registers used in the present study are maintained by Statistics Sweden and the National Board of Health and Welfare.

This work was supported by grants to Dr Bengt Zöller from the Swedish Heart-Lung Foundation and Region Skåne (REGSKANE-124611), to Dr Kristina Sundquist from the Swedish Research Council (K2009-70X-15428-05-3; K2012-70X-15428-08-3), to Dr Jan Sundquist from the Swedish Council for Working Life and Social Research (2007-1754) and the Swedish Freemasons Foundation as well as ALF funding from Region Skåne awarded to Jan Sundquist and Kristina Sundquist.

The funding sources had no role in the design, conduct, or analysis of the study or in the decision to submit the manuscript for publication.

\section{Author details}

${ }^{1}$ Center for Primary Health Care Research, CRC, Skåne University Hospital, Building 28, Floor 11, Jan Waldenströms gata 35, Malmö S-205 02, Sweden. ${ }^{2}$ Stanford Prevention Research Center, Stanford University School of Medicine, Stanford, California, USA. 
Received: 3 July 2012 Accepted: 30 November 2012

Published: 10 December 2012

\section{References}

1. Estes NA 3rd, Sacco RL, Al-Khatib SM, Ellinor PT, Bezanson J, Alonso A, Antzelevitch C, Brockman RG, Chen PS, Chugh SS, Curtis AB, DiMarco JP, Ellenbogen KA, Epstein AE, Ezekowitz MD, Fayad P, Gage BF, Go AS, Hlatky MA, Hylek EM, Jerosch-Herold M, Konstam MA, Lee R, Packer DL, Po SS, Prystowsky EN, Redline S, Rosenberg Y, Van Wagoner DR, Wood KA, et al: American Heart Association atrial fibrillation research summit: a conference report from the American Heart Association. Circulation 2011 124:363-372.

2. Lip GY, Tse HF, Lane DA: Atrial fibrillation. Lancet 2012, 379:648-661.

3. Schoonderwoerd BA, Smit MD, Pen L, Van Gelder IC: New risk factors for atrial fibrillation: causes of 'not-so-lone atrial fibrillation'. Europace 2008, 10:668-673

4. Evans W, Swann P: Lone auricular fibrillation. Br Heart J 1954, 16:189-194. 5. Potpara TS, Lip GY: Lone atrial fibrillation: what is known and what is to come. Int J Clin Pract 2011, 65:446-457.

6. Wolf L: Familial auricular fibrillation. N Engl J Med 1943, 229:396-397.

7. Darbar D, Herron KJ, Ballew JD, Jahangir A, Gersh BJ, Shen WK, Hammill SC, Packer DL, Olson TM: Familial atrial fibrillation is a genetically heterogeneous disorder. J Am Coll Cardiol 2003, 41:2185-2192.

8. Fox CS, Parise H, D'Agostino RB Sr, Lloyd-Jones DM, Vasan RS, Wang T, Levy D, Wolf PA, Benjamin EJ: Parental atrial fibrillation as a risk factor for atrial fibrillation in offspring. JAMA 2004, 291:2851-2855.

9. Ellinor PT, Yoerger DM, Ruskin JN, MacRae CA: Familial aggregation in lone atrial fibrillation. Hum Genet 2005, 118:179-184.

10. Arnar DO, Thorvaldsson S, Manolio TA, Thorgeirsson G, Kristjansson K, Hakonarson $\mathrm{H}$, Stefansson K: Familial aggregation of atrial fibrillation in Iceland. Eur Heart J 2006, 27:708-712.

11. Marcus GM, Smith LM, Vittinghoff E, Tseng ZH, Badhwar N, Lee BK, Lee RJ, Scheinman MM, Olgin JE: A first-degree family history in lone atrial fibrillation patients. Hear Rhythm 2008, 5:826-830

12. Chen LY, Herron KJ, Tai BC, Olson TM: Lone atrial fibrillation: influence of familial disease on gender predilection. J Cardiovasc Electrophysio/ 2008, 19:802-806.

13. Christophersen IE, Ravn LS, Budtz-Joergensen E, Skytthe A, Haunsoe S, Svendsen $\mathrm{JH}$, Christensen K: Familial aggregation of atrial fibrillation: a study in Danish twins. Circ Arrhythm Electrophysiol 2009, 2:378-383.

14. Yang $Y Q$, Zhang $X L$, Wang $X H$, Tan HW, Shi HF, Fang WY, Liu X: Familial aggregation of lone atrial fibrillation in the Chinese population. Intern Med 2010, 49:2385-2391.

15. Lubitz SA, Yin X, Fontes JD, Magnani JW, Rienstra M, Pai M, Villalon ML Vasan RS, Pencina MJ, Levy D, Larson MG, Ellinor PT, Benjamin EJ: Association between familial atrial fibrillation and risk of new-onset atrial fibrillation. JAMA 2010, 304:2263-2269.

16. Brugada R, Tapscott T, Czernuszewicz G, Marian AJ, Iglesias A, Mont L Brugada J, Girona J, Domingo A, Bachinski LL, Roberts R: Identification of a genetic locus for familial atrial fibrillation. N Engl J Med 1997, 336:905-911.

17. Gudbjartsson DF, Arnar DO, Helgadottir A, Gretarsdottir S, Holm H, Sigurdsson A, Jonasdottir A, Baker A, Thorleifsson G, Kristjansson K, Palsson A, Blondal T, Sulem P, Backman VM, Hardarson GA, Palsdottir E, Helgason A Sigurjonsdottir R, Sverrisson JT, Kostulas K, Ng MC, Baum L, So WY, Wong KS, Chan JC, Furie KL, Greenberg SM, Sale M, Kelly P, MacRae CA, et al: Variants conferring risk of atrial fibrillation on chromosome $4 q 25$. Nature 2007, 448:353-357

18. Gudbjartsson DF, Holm H, Gretarsdottir S, Thorleifsson G, Walters GB, Thorgeirsson G, Gulcher J, Mathiesen EB, Njølstad I, Nyrnes A, Wilsgaard T, Hald EM, Hveem K, Stoltenberg C, Kucera G, Stubblefield T, Carter S, Roden D, Ng MC, Baum L, So WY, Wong KS, Chan JC, Gieger C, Wichmann HE, Gschwendtner A, Dichgans M, Kuhlenbäumer G, Berger K, Ringelstein EB, et al: A sequence variant in ZFHX3 on $16 q 22$ associates with atrial fibrillation and ischemic stroke. Nat Genet 2009, 41:876-878.

19. Benjamin EJ, Rice KM, Arking DE, Pfeufer A, van Noord C, Smith AV, Schnabel RB, Bis JC, Boerwinkle E, Sinner MF, Dehghan A, Lubitz SA, D'Agostino RB Sr, Lumley T, Ehret GB, Heeringa J, Aspelund T, Newton-Cheh C, Larson MG, Marciante KD, Soliman EZ, Rivadeneira F, Wang TJ, Eiríksdottir G, Levy D, Psaty BM, Li M, Chamberlain AM, Hofman A, Vasan RS, et al: Variants in ZFHX3 are associated with atrial fibrillation in individuals of European ancestry. Nat Genet 2009, 41:879-881.
20. Ellinor PT, Lunetta KL, Glazer NL, Pfeufer A, Alonso A, Chung MK, Sinner MF, de Bakker PI, Mueller M, Lubitz SA, Fox E, Darbar D, Smith NL, Smith JD, Schnabel RB, Soliman EZ, Rice KM, Van Wagoner DR, Beckmann BM, van Noord C, Wang K, Ehret GB, Rotter Jl, Hazen SL, Steinbeck G, Smith AV, Launer LJ, Harris TB, Makino S, Nelis M, et al: Common variants in KCNN3 are associated with lone atrial fibrillation. Nat Genet 2010, 42:240-244.

21. Wakili R, Voigt N, Kääb S, Dobrev D, Nattel S: Recent advances in the molecular pathophysiology of atrial fibrillation. J Clin Invest 2011, 121:2955-2968.

22. Parvez B, Darbar D: The "missing link" in atrial fibrillation heritability. J Electrocardiol 2011, 44:641-644.

23. Olesen MS, Jespersen T, Nielsen JB, Liang B, Møller DV, Hedley $P$, Christiansen M, Varró A, Olesen SP, Haunsø S, Schmitt N, Svendsen JH: Mutations in sodium channel $\beta$-subunit SCN3B are associated with earlyonset lone atrial fibrillation. Cardiovasc Res 2011, 89:786-793.

24. Watanabe H, Darbar D, Kaiser DW, Jiramongkolchai K, Chopra S, Donahue BS, Kannankeril PJ, Roden DM: Mutations in sodium channel beta1- and beta2subunits associated with atrial fibrillation. Circ Arrhythm Electrophysiol 2009, 2:268-275

25. Ellinor $\mathrm{PT}$, Lunetta $\mathrm{KL}$, Albert $\mathrm{CM}$, Glazer NL, Ritchie MD, Smith $\mathrm{AV}$, Arking DE, Müller-Nurasyid M, Krijthe BP, Lubitz SA, Bis JC, Chung MK, Dörr M, Ozaki K, Roberts JD, Smith JG, Pfeufer A, Sinner MF, Lohman K, Ding J, Smith NL, Smith JD, Rienstra M, Rice KM, Van Wagoner DR, Magnani JW, Wakili R, Clauss S, Rotter Jl, Steinbeck G, et al: Meta-analysis identifies six new susceptibility loci for atrial fibrillation. Nat Genet 2012, 44:670-675

26. Liu T, Li G, Li L, Korantzopoulos P: Association between C-reactive protein and recurrence of atrial fibrillation after successful electrical cardioversion: a meta-analysis. J Am Coll Cardiol 2007, 49:1642-1648.

27. Gurevitz OT, Varadachari CJ, Ammash NM, Malouf JF, Rosales AG, Herges RM, Bruce CJ, Somers VK, Hammill SC, Gersh BJ, Friedman PA: The effect of patient sex on recurrence of atrial fibrillation following successful direct current cardioversion. Am Heart J 2006, 152(155):9-13.

28. Guglin M, Maradia K, Chen R, Curtis AB: Relation of obesity to recurrence rate and burden of atrial fibrillation. Am J Cardiol 2011, 107:579-582.

29. Disertori M, Lombardi F, Barlera S, Latini R, Maggioni AP, Zeni P, Di Pasquale G, Cosmi F, Franzosi MG, GISSI-AF Investigators: Clinical predictors of atrial fibrillation recurrence in the Gruppo Italiano per lo Studio della Sopravvivenza nell'Infarto Miocardico-Atrial Fibrillation (GISSI-AF) trial. Am Heart J 2010, 159:857-863.

30. Schmidt M, Rieber J, Daccarett M, Marschang H, Sinha AM, Biggar P, Jung $P$, Ketteler M, Brachmann J, Rittger H: Relation of recurrence of atrial fibrillation after successful cardioversion to renal function. Am J Cardiol 2010, 105:368-372

31. Latini R, Masson S, Pirelli S, Barlera S, Pulitano G, Carbonieri E, Gulizia M, Vago T, Favero C, Zdunek D, Struck J, Staszewsky L, Maggioni AP, Franzosi MG, Disertori M, on the behalf of the GISSI-AF Investigators: Circulating cardiovascular biomarkers in recurrent atrial fibrillation: data from the GISSI-atrial fibrillation trial. J Intern Med 2011, 269:160-171.

32. Tang $Y$, Yang $H$, Qiu J: Relationship between brain natriuretic peptide and recurrence of atrial fibrillation after successful electrical cardioversion: a meta-analysis. J Int Med Res 2011, 39:1618-1624.

33. Rosen M, Hakulinen T: Use of disease registers. In Handbook of epidemiology Edited by Ahrens W, Pigeot I. Springer-Verlag: Berlin; 2005:231-252.

34. Lichtenstein P, Yip BH, Björk C, Pawitan Y, Cannon TD, Sullivan PF, Hultman CH: Common genetics determinants of schizophrenia and bipolar disorders in Swedish families: a population-based study. Lancet 2009, 373:234-239.

35. Zöller B, Li X, Ohlsson H, Sundquist J, Sundquist K: Venous thromboembolism does not share strong familial susceptibility with ischemic stroke: a nationwide family study in Sweden. Circ Cardiovasc Genet 2011, 4:484-490

36. Zöller B, Li X, Sundquist J, Sundquist K: Age- and gender-specific familial risks for venous thromboembolism: a nationwide epidemiological study based on hospitalizations in Sweden. Circulation 2011, 124:1012-1020.

37. Ludvigsson JF, Andersson E, Ekbom A, Feychting M, Kim JL, Reuterwall C, Heurgren M, Olausson PO: External review and validation of the Swedish national inpatient register. BMC Publ Health 2011, 11:450.

38. Smith JG, Platonov PG, Hedblad B, Engström G, Melander O: Atrial fibrillation in the Malmö Diet and Cancer study: a study of occurrence, risk factors and diagnostic validity. Eur J Epidemio/ 2010, 25:95-102. 
39. Rothman K, Greenland S: Modern Epidemiology. 3rd edition. Philadelphia: Lippincott-Raven; 2008

40. Burton PR, Tobin MD, Hopper JL: Key concepts in genetic epidemiology. Lancet 2005, 366:941-951.

41. Hemminki K, Bermejo JL: Constraints for genetic association studies imposed by attributable fraction and familial risks. Carcinogenesis 2007, 28:648-656.

doi:10.1186/1471-2261-12-121

Cite this article as: Zöller et al:: Family history as a risk factor for

recurrent hospitalization for lone atrial fibrillation: a nationwide family study in Sweden. BMC Cardiovascular Disorders 2012 12:121.

\section{Submit your next manuscript to BioMed Central and take full advantage of:}

- Convenient online submission

- Thorough peer review

- No space constraints or color figure charges

- Immediate publication on acceptance

- Inclusion in PubMed, CAS, Scopus and Google Scholar

- Research which is freely available for redistribution 